\title{
Dissemination of shock waves in thin isotropic plates
}

\author{
František Klimenda ${ }^{1, *}$, Josef Soukup ${ }^{1}$, Milan Žmindák ${ }^{2}$, and Blanka Skočilasová ${ }^{1}$ \\ ${ }^{1}$ Faculty of Mechanical Engineering, J. E. Purkyne University in Usti nad Labem. Pasteurova 3334/7, \\ 40096 Usti nad Labem. Czech Republic \\ ${ }^{2}$ Faculty of Mechanical Engineering, University of Zilina, Univerzitná 1, 01026 Žilina, Slovak \\ Republic
}

\begin{abstract}
The article deals with the propagation of shock waves in thin isotropic plates. The solution is done analytically. The geometric model of Kirchhoff and Rayleigh was used for the solution. Material model was used Hook. The shock wave is induced by the impact of the punch into the centre of the plate. The longitudinal waves propagate in the $x$ and $y$ axis, the transverse wave propagates in the axis. Comparison of the longitudinal and transverse wave propagation of both models at selected points is made. Comparisons are displacements, velocities and tensions in $x, y$ and $z$ axis, depending on time. The rectangular plate is made of unidirectional rolled aluminium sheet of high purity. The plate is around the perimeter fixed. The MATLAB program was used to solve this problem.
\end{abstract}

Keywords: plate, wave, MATLAB

\section{Introduction}

The issue of vibrations of thin plates is solved for more than 200 years. Euler made the first mathematical expression on the plates in 1776 . He analysed the free oscillation of the plates. After that, many scientists, such as Chladni, Bernoulli and others, worked on the issue, all of which came from the work of Euller. Significant progress in solving these problems occurred in 1850, when Kirchhoff published his theory of thin plates [1,2]. Other authors followed this basic theory. Rayleigh extended Kirchhoff's geometric model by the effect of crosssectional rotation and corresponding inertial effects. Flügge introduced the effect of shear on the resulting vertical displacement, but did not consider turning the cross-sections. Timoshenko-Mindlin's model considers both cross-section and shear. In addition to the above-mentioned core model correction models, some additional corrections were proposed to improve the approximation [2].

\footnotetext{
${ }^{*}$ Corresponding author: frantisek.klimenda@ujep.cz

Reviewers: Milan Sága, Robert Zalewski
} 
In addition to these geometric models, different models of materials. The basic material model is Hook's, which was further developed by Vight-Kelvin, Maxwell, and Zener.

The article deals with the examination of the transient oscillation of the thin isotropic rectangular plate that is around the perimeter fixed. The solution of this plate is done analytically. Kirchhoff and Rayleigh's geometric model and Hook's material model were selected. The thin plate of dimensions $a \times b \times h$ is loaded in its geometric center by the impact force $F(t)$ induced by the impact of the punch of the radius $\mathrm{c}$ on the upper face of the plate (Fig. 1). When the deformation plate from the propagating waves are assumed small deformation (Fig. 2).

The aim of the solution is to compare the deformations (displacement), the propagation velocity of the shockwave and the tensions of both plate models.

\section{Solution}

Based on the geometry of the plate, the basic relations for the displacement $u, v, w$ in the direction of the axes $x, y$ and $z$ were derived from the propagating shock wave $[2,3]$.

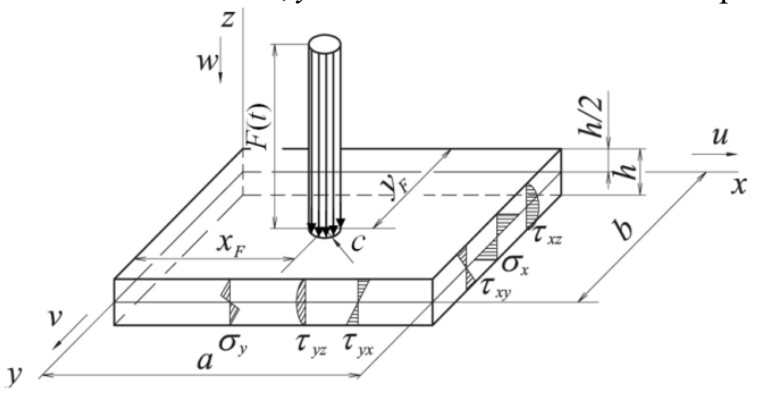

Fig. 1. Scheme of load plate [2]

Legend: $\mathrm{a}, \mathrm{b}, \mathrm{h}$ - dimensions of the plate, $\mathrm{c}$ - radius of impact, $F(t)$ - load force, $x F, y F-$ force coordinates, $\sigma \mathrm{x}, \sigma \mathrm{y}-$ bending stresses, $\tau \mathrm{yx}, \tau \mathrm{xy}-$ torsional stresses, $\tau \mathrm{xz}, \tau \mathrm{yz}-$ shear force

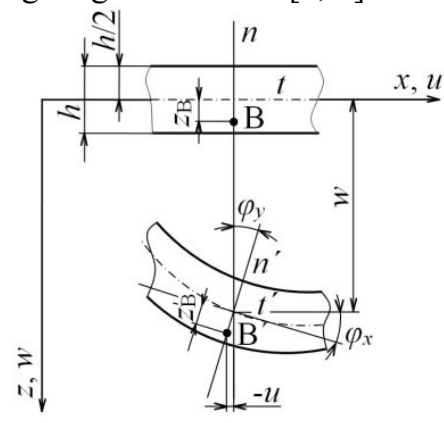

Fig. 2. Geometry of plate deformation [2]

Legend: $\mathrm{n}, \mathrm{n}^{\prime}$ - normals, $\mathrm{t}, \mathrm{t}^{\prime}$ - tangents, $\mathrm{u}, \mathrm{w}-$ displacementin $\mathrm{x}$ and $\mathrm{y}$ direction, $\varphi x, \varphi y-$ angles of the cut in the direction of the $\mathrm{x}$ and $\mathrm{y}$ axes, $\mathrm{B}, \mathrm{B}^{\prime}-$ watch point, $\mathrm{zB}, \mathrm{zB}^{\prime}$ - distance of point $\mathrm{B}, \mathrm{h}-$ thickness of the plate

The displacement $u, v$ and $w$ in the direction of the $x, y$ and $z$ axis from the propagating chock wave are

$$
u=u(x, y, z, t) \quad v=v(x, y, z, t) \quad w=w(x, y, t)
$$

After deformation of the plate, the normal, resp. the tangent at point $\mathrm{B}$ is rotated by the angle $\varphi$ - with respect to the $x$ axis by the angle $\varphi_{x}$, with respect to the $y$ axis of the angle $\varphi_{y}$. Then, the displacement along the $x$ axis and the $y$ axis direction for both models can be expressed as

$$
u=-z \varphi_{\mathrm{x}}
$$

The velocities of wave propagation $i \cdot \cdot$ are for both models the same

$$
\dot{u}=\frac{\partial u}{\partial t} \quad \dot{v}=\frac{\partial v}{\partial t} \quad \dot{w}=\frac{\partial w}{\partial t}
$$

Vertical displacement of the isotropic thin plate $w(x, y, t)[2,3]$ 
for the Kirchchoff's model

$$
\begin{gathered}
w(x, y, t)=\frac{16}{a b c} \frac{F_{0}}{\rho h} \sum_{m=1}^{\infty} \sum_{n=1}^{\infty} \frac{J_{1}\left(\gamma_{m n} c\right)}{\gamma_{m n}} \frac{\sin \alpha_{n} x_{F} \cos \beta_{m} y_{F}}{\omega_{m n}^{2}} \sin \alpha_{n} x \sin \beta_{m} y \sin ^{2} \frac{\omega_{m n}}{2} t \\
\omega_{m n}=\left(\alpha_{n}^{2}+\beta_{m}^{2}\right) \sqrt{\frac{D}{\rho h}}=\left(\alpha_{n}^{2}+\beta_{m}^{2}\right) \frac{c h}{\sqrt{12}}
\end{gathered}
$$

for the Rayleigh's model

$$
\begin{gathered}
w(x, y, t)=\frac{16}{a b c} \frac{F_{0}}{\rho h} \sum_{m=1 n=1}^{\infty} \sum^{\infty} \frac{J_{1}\left(\gamma_{m n} c\right)}{\gamma_{m n}} \frac{\sin \alpha_{n} x_{F} \cos \beta_{m} y_{F}}{\left[\frac{h^{2}}{12}\left(\alpha_{n}^{2}+\beta_{m}^{2}\right)+1\right] \omega_{m n}^{2}} \sin \alpha_{n} x \sin \beta_{m} y \sin ^{2} \frac{\omega_{m n}}{2} t \\
\omega_{m n}=\frac{\alpha^{2}+\beta^{2}}{\sqrt{\frac{h^{2}}{12}\left(\alpha_{n}^{2}+\beta_{m}^{2}\right)+1}} \sqrt{\frac{D}{\rho h}}=\frac{\alpha^{2}+\beta^{2}}{\sqrt{\frac{h^{2}}{12}\left(\alpha_{n}^{2}+\beta_{m}^{2}\right)+1} \frac{c h}{\sqrt{12}}}
\end{gathered}
$$

The coefficient $\gamma_{m n}$, the plate stiffness $D$ and the constants $\alpha, \beta$ are the same for both models

$$
\gamma_{m n}=\sqrt{\alpha_{n}^{2}+\beta_{m}^{2}} \quad D=\frac{E h^{3}}{12\left(1-\mu^{2}\right)} \quad \alpha_{n}=n \frac{\pi}{a} \quad \beta_{m}=m \frac{\pi}{b}
$$

Normal and tangential stresses $\sigma_{x}, \sigma_{y}$ are for both model the same

$$
\begin{aligned}
& \sigma_{x}(x, y, z, t)=-\frac{z E x}{1-\mu_{x y} \mu_{y x}}\left(\frac{\partial^{2} w}{\partial x^{2}}+\mu_{x y} \frac{\partial^{2} w}{\partial y^{2}}\right) \\
& \sigma_{y}(x, y, z, t)=-\frac{z E y}{1-\mu_{x y} \mu_{y x}}\left(\frac{\partial^{2} w}{\partial y^{2}}+\mu_{x y} \frac{\partial^{2} w}{\partial x^{2}}\right)
\end{aligned}
$$

where $a, b, h$-dimensions of the plate, $c$ - radius of punch, $\rho$-density of the plate material, $F_{0}$ - load force, $J_{1}\left(\gamma_{m n c}\right)$ - Bessel's first-order function, the first order for the $\gamma_{m n c}$ argument, $\alpha, \beta$ - constants, $m, n$ - variables, $x_{F}, y_{F}$ - force coordinates, $x, y, z$ - the coordinate of the examined point, $\omega_{m n}$ - own frequency, $t$ - time, $D$ - plate stiffness, $E, G-$ tensile and shear modulus, $\mu$ - Poisson's number.

\section{Results}

Wave propagation in a thin plate was analytically solved in the MATLAB program for the Al 99.9 isotropic aluminium plate $[5,6,7,8]$. The dimensions of the plate were $0.2 \times 0.1 \times 0.002 \mathrm{~m}$. The material properties are shown in Tab. 1 .

Table 1. Material properties of Al plate

\begin{tabular}{|c|c|c|c|}
\hline Název & Označení & Jednotka & Hodnota \\
\hline Modul pružnosti v tahu & $E$ & $\mathrm{~Pa}$ & $7.1 \times 10^{10}$ \\
\hline Poissonovo číslo & $\mu$ & - & 0.34 \\
\hline Hustota & $\rho$ & $\mathrm{kg} \cdot \mathrm{m}^{-3}$ & 2699 \\
\hline
\end{tabular}


The plate was about perimeter fixed and in the center of impact $\left(x_{F}=0.1 \mathrm{~m}, y_{F}=0.05 \mathrm{~m}\right)$ was loaded with a force of $F(t)=1 \mathrm{~N}$ from a punch with a radius $c=0.025 \mathrm{~m}$ (Fig. 3). Size of the displacements, velocity and deformations of the wave propagating in a thin plate for the Kirchchoff and Rayleigh models were determined at the points $\mathrm{K}_{1}[0.02 ; 0.00 ; 0.00], \mathrm{K}_{2}$ $[0.00 ; 0.02 ; 0.00]$.

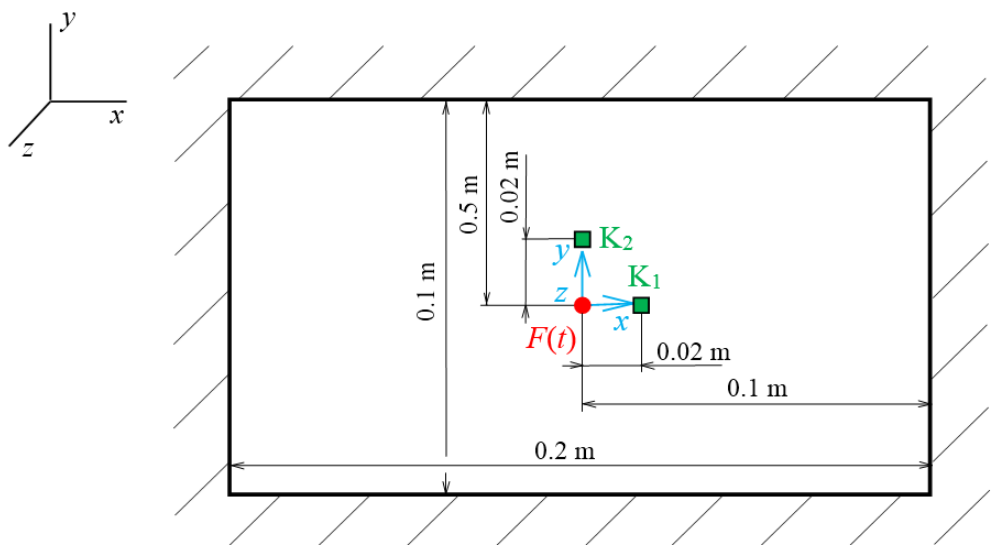

Fig. 3. Plate dimensions and centre of impact, Legend: $F(t)$ - load force in centre of plate, $\mathrm{K}_{1}, \mathrm{~K}_{2}$ - points

On Fig. 4 and Fig. 5 are shown the waveforms $w$ (in the $z$ axis) at points K1, K2 for the Kirchhoff and Rayleigh models. The corresponding numerical values are shown in Tab. 2.

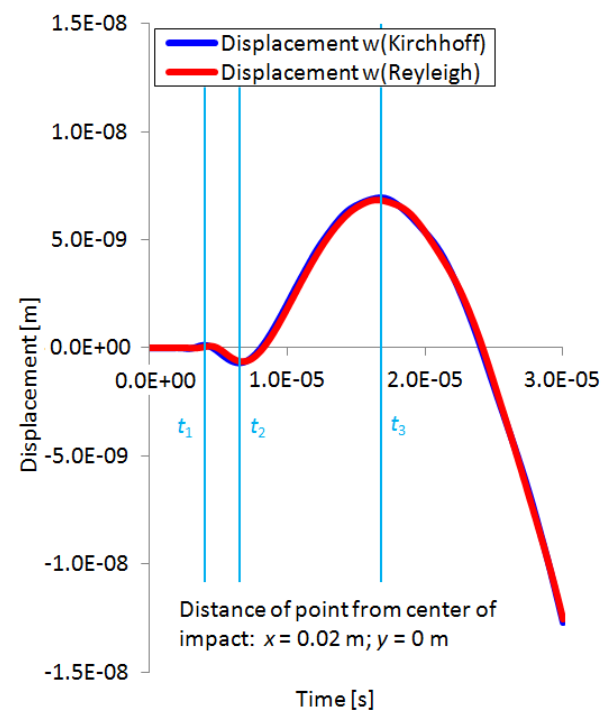

Fig. 4. Wave displacement after impact $\mathrm{w}$ in point $\mathrm{K}_{1}$ for Kirchchoff's and Reyleigh's model

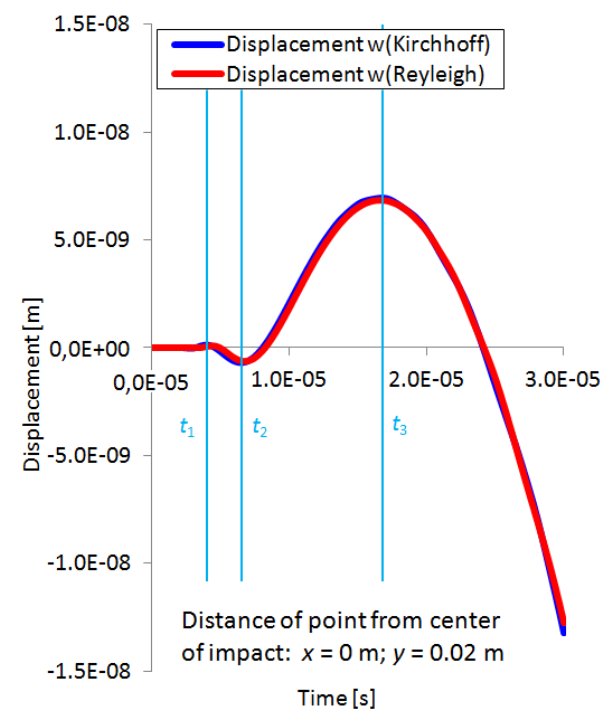

Fig. 5. Wave displacement after impact $\mathrm{w}$ in point $\mathrm{K}_{2}$ for Kirchchoff's and Reyleigh's model 
Table 2. Wave displacement after impact $(w)$ in point $\mathrm{K}_{1}$ and $\mathrm{K}_{2}$

\begin{tabular}{|c|c|c|c|c|c|}
\hline \multicolumn{2}{|c|}{ Point } & \multicolumn{2}{|c|}{ K$_{\mathbf{1}}$} & \multicolumn{2}{c|}{$\mathbf{K}_{\mathbf{2}}$} \\
\hline \multicolumn{2}{|c|}{ Time [s] } & \multicolumn{4}{|c|}{ Displacement $\boldsymbol{w}[\mathbf{m}]$} \\
\cline { 3 - 6 } & & Kirchhoff & Reyleigh & Kirchhoff & Reyleigh \\
\hline$t_{1}$ & $4.000 \times 10^{-6}$ & $1.284 \times 10^{-10}$ & $5.259 \times 10^{-11}$ & $1.284 \times 10^{-10}$ & $5.437 \times 10^{-11}$ \\
\hline$t_{2}$ & $6.500 \times 10^{-6}$ & $-6.864 \times 10^{-10}$ & $-6.132 \times 10^{-10}$ & $-6.859 \times 10^{-10}$ & $-6.133 \times 10^{-10}$ \\
\hline$t_{3}$ & $1.680 \times 10^{-5}$ & $6.966 \times 10^{-9}$ & $6.825 \times 10^{-9}$ & $6.939 \times 10^{-9}$ & $6.830 \times 10^{-9}$ \\
\hline
\end{tabular}

From the above it follows that the profile of the transverse displacement is the same at both points of observation in both models. Both points are equally distant from the shock center, the point $\mathrm{K}_{1}$ lies $0.02 \mathrm{~m}$ on the $x$ axis, point $\mathrm{K}_{2}$ at the same distance on the $y$ axis (see Fig. 3). In transverse displacement at Rayleigh's model does not have the effect of crosssectional rotation, this effect is only apparent in longitudinal waves. (see below).

On Fig. 6 and Fig. 7 are shows displacements $u, v$ (in $x$ and $y$ axis) at points $\mathrm{K}_{1}, \mathrm{~K}_{2}$ for Kirchhoff and Rayleigh models. The corresponding numeric values are shown in Tab. 3. At point $K_{1}$ is the displacement in the $y$ axis direction of zero (displacement $v$ ). At point $K_{2}$ is the displacement in the $x$ axis direction of zero (displacement $u$ ).

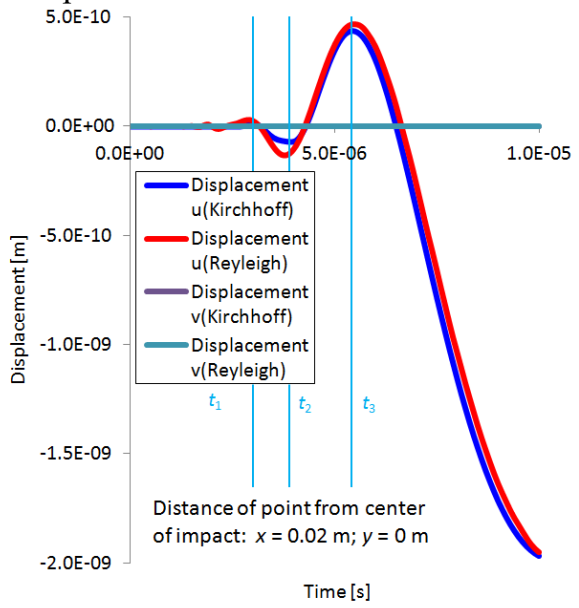

Fig. 6. Wave displacement after impact $u, v$ in point $\mathrm{K}_{1}$ for Kirchchoff's and Reyleigh's model

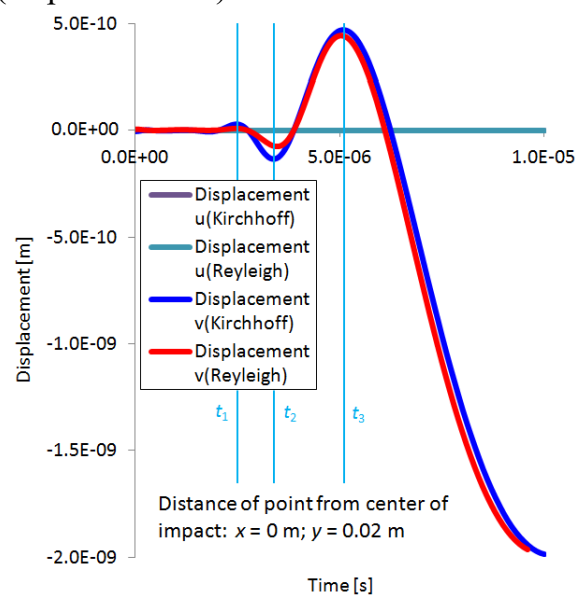

Fig. 7. Wave displacement after impact $u, v$ in point $\mathrm{K}_{2}$ for Kirchchoff's and Reyleigh's model

Table 3. Wave displacement after impact $(u, v)$ in point $\mathrm{K}_{1}$ and $\mathrm{K}_{2}$

\begin{tabular}{|c|c|r|r|r|r|}
\hline \multicolumn{2}{|c|}{ Point } & \multicolumn{2}{c|}{K$_{\mathbf{1}}$} & \multicolumn{2}{c|}{$\mathbf{K}_{\mathbf{2}}$} \\
\hline \multicolumn{2}{|c}{ Time [s] } & \multicolumn{2}{c|}{ Displacement $\boldsymbol{u}[\mathrm{m}]$} & \multicolumn{2}{c|}{ Displacement $\boldsymbol{v}[\mathrm{m}]$} \\
\cline { 3 - 6 } & Kirchhoff & Reyleigh & Kirchhoff & Reyleigh \\
\hline$t_{1}$ & $3.000 \times 10^{-6}$ & $1.254 \times 10^{-11}$ & $2.383 \times 10^{-11}$ & $3.362 \times 10^{-11}$ & $2.391 \times 10^{-12}$ \\
\hline$t_{2}$ & $3.900 \times 10^{-6}$ & $-7.081 \times 10^{-11}$ & $-1.246 \times 10^{-10}$ & $-1.294 \times 10^{-10}$ & $9.947 \times 10^{-12}$ \\
\hline$t_{3}$ & $5.400 \times 10^{-6}$ & $4.373 \times 10^{-10}$ & $4.647 \times 10^{-10}$ & $4.716 \times 10^{-10}$ & $2.118 \times 10^{-10}$ \\
\hline
\end{tabular}

The distance of the points under consideration is from the center of impact in both directions the same, so the wave will arrive at both points at the same time. Differences during displacement between the models are due to the fact that Rayleigh's computational model involves the effect of cross-section rotation, whereas the Kirchhoff model does not.

On Fig. 8 and Fig. 9 are show velocities $\dot{w}$ (in $z$ axis) at points $\mathrm{K}_{1}, \mathrm{~K}_{2}$ for Kirchhoff and Rayleigh models. The corresponding numeric values are shown in Tab. 4. 


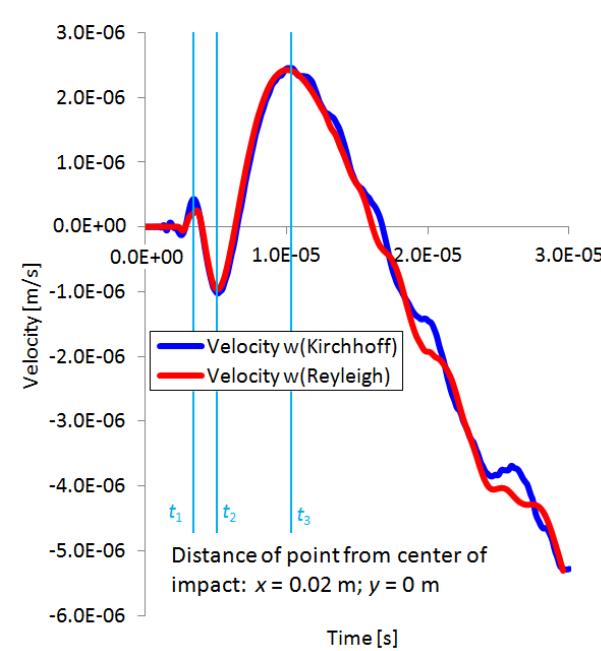

Fig. 8. Wave velocity after impact $\dot{w}$ in point $\mathrm{K}_{1}$ for Kirchchoff's and Reyleigh's model

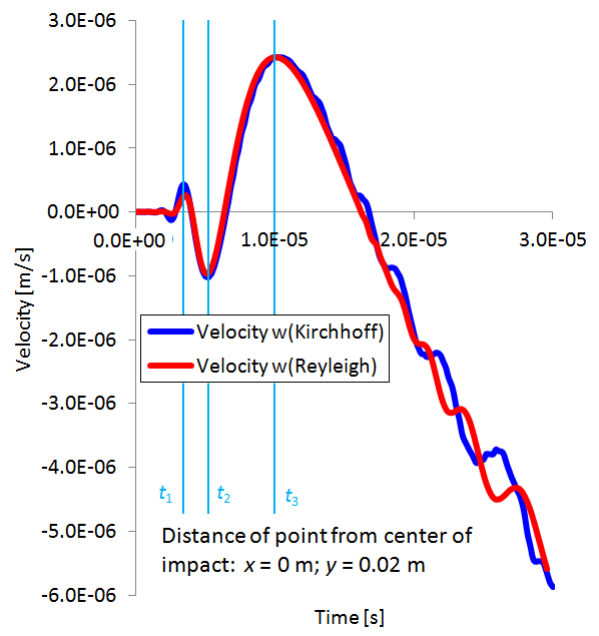

Fig. 9. Wave velocity after impact $\dot{w}$ in point $\mathrm{K}_{2}$ for Kirchchoff's and Reyleigh's model

Table 4. Wave velocity after impact $(\dot{w})$ in point $K_{1}$ and $K_{2}$

\begin{tabular}{|c|c|r|r|r|r|}
\hline \multicolumn{2}{|c|}{ Point } & \multicolumn{2}{|c|}{ K$_{\mathbf{1}}$} & \multicolumn{2}{c|}{ K$_{\mathbf{2}}$} \\
\hline \multicolumn{2}{|c|}{ Time [s] } & \multicolumn{3}{|c|}{ Velocity $\dot{\boldsymbol{w}}\left[\mathbf{m} \cdot \mathbf{s}^{-1}\right]$} \\
\cline { 3 - 6 } & & Kirchhoff & \multicolumn{1}{c|}{ Reyleigh } & \multicolumn{1}{c|}{ Kirchhoff } & \multicolumn{1}{c|}{ Reyleigh } \\
\hline$t_{1}$ & $3.400 \times 10^{-6}$ & $4.292 \times 10^{-7}$ & $2.081 \times 10^{-7}$ & $4.316 \times 10^{-7}$ & $2.411 \times 10^{-7}$ \\
\hline$t_{2}$ & $5.100 \times 10^{-6}$ & $-1.027 \times 10^{-6}$ & $-9.666 \times 10^{-7}$ & $-1.022 \times 10^{-6}$ & $-9.569 \times 10^{-7}$ \\
\hline$t_{3}$ & $1.030 \times 10^{-5}$ & $2.452 \times 10^{-6}$ & $2.409 \times 10^{-6}$ & $2.425 \times 10^{-6}$ & $2.410 \times 10^{-6}$ \\
\hline
\end{tabular}

At longer times is noticeable smoother velocity changes in the Rayleigh model. It's probably due to the fact that the equation is enhanced by the influence of the rotation section. Equations for speed are given by the derivation of the feed. At Kirchhoff, the effect of not turning the cross-section will be reflected after derivation of greater deviation in velocity $(\dot{w}(t))$. The longer time during the velocity on both models, show the wave reflections from the bottom edge of the plate.

On Fig. 10 and Fig. 11 are shows velocities $\dot{u}, \dot{v}$ (in $x$ and $y$ axis) at points K1, K2 for Kirchhoff and Rayleigh models. The corresponding numeric values are shown in Tab. 5. At point $\mathrm{K}_{1}$ is the velocity in the $y$ axis direction of zero (velocity $\dot{v}$ ). At point $\mathrm{K}_{2}$ is the velocity in the $x$ axis direction of zero (velocity $u$ ).

Table 5. Wave velocity after impact $(\dot{u}, \dot{v})$ in point $\mathrm{K}_{1}$ and $\mathrm{K}_{2}$

\begin{tabular}{|c|c|c|c|c|c|}
\hline \multicolumn{2}{|c|}{ Point } & \multicolumn{2}{c|}{ K$_{\mathbf{1}}$} & \multicolumn{2}{c|}{$\mathbf{K}_{\mathbf{2}}$} \\
\hline \multicolumn{2}{|c|}{ Time [s] } & \multicolumn{2}{|c|}{ Velocity $\dot{\boldsymbol{i}}\left[\mathbf{m} \cdot \mathbf{s}^{-1}\right]$} & \multicolumn{2}{c|}{ Velocity $\dot{\boldsymbol{v}}\left[\mathbf{m} \cdot \mathbf{s}^{-1}\right]$} \\
\cline { 3 - 6 } & & Kirchhoff & Kirchhoff & Kirchhoff & Reyleigh \\
\hline$t_{1}$ & $2.300 \times 10^{-6}$ & $8.711 \times 10^{-5}$ & $8.711 \times 10^{-5}$ & $8.716 \times 10^{-5}$ & $1.602 \times 10^{-5}$ \\
\hline$t_{2}$ & $3.000 \times 10^{-6}$ & $-2.895 \times 10^{-4}$ & $-2.895 \times 10^{-4}$ & $-2.895 \times 10^{-4}$ & $-1.432 \times 10^{-4}$ \\
\hline$t_{3}$ & $4.100 \times 10^{-6}$ & $5.579 \times 10^{-4}$ & $5.579 \times 10^{-4}$ & $5.579 \times 10^{-4}$ & $5.387 \times 10^{-4}$ \\
\hline
\end{tabular}




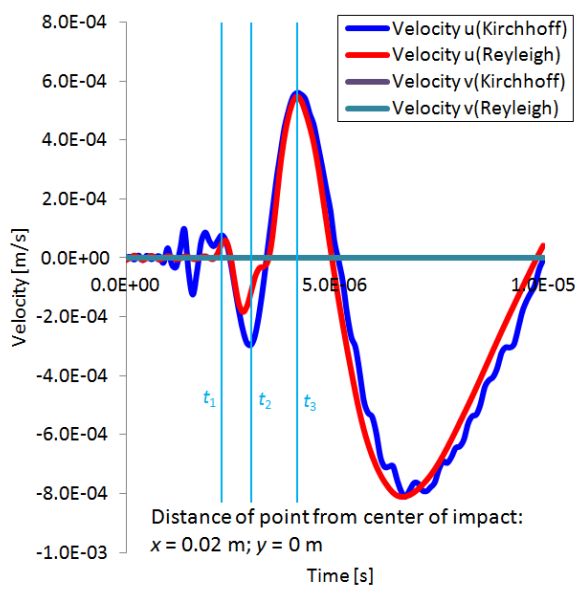

Fig. 10. Wave velocity after impact $\dot{u}, \dot{v}$ in point $\mathrm{K}_{1}$ for Kirchchoff's and Reyleigh's model

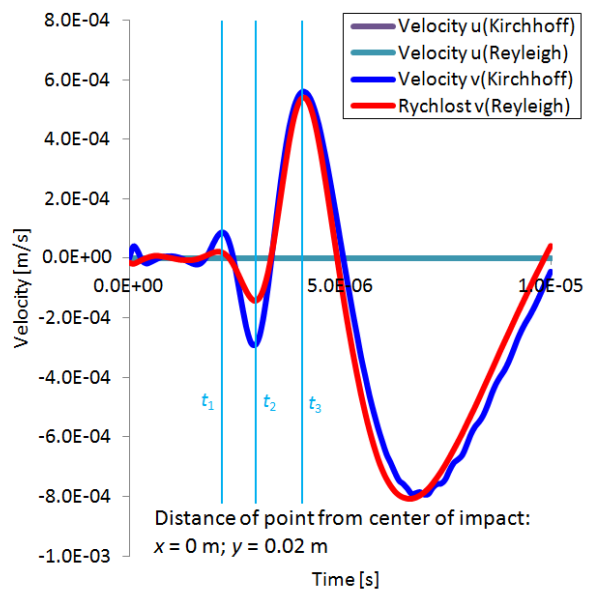

Fig. 11. Wave velocity after impact $\dot{u}, \dot{v}$ in point $\mathrm{K}_{2}$ for Kirchchoff's and Reyleigh's model

It can be seen from the course of velocity that at longitudinal velocities the influence of the cross-sectional rotation of the Rayleigh model is more pronounced. Essentially, this means that the effect of rotation is at the cross-section of the longitudinal wave undulations substantially greater than during the transverse velocity. It can be said that Rayleigh's model is closer to reality than the basic Kirchhoff model.

On Fig. 12 and Fig. 15 are shows the normal and tangential stresses $\sigma_{x}, \sigma_{y}$ (in $x$ and $y$ axis) at points $\mathrm{K}_{1}, \mathrm{~K}_{2}$ for the Kirchhoff and Rayleigh models. We assume that the waves propagate from the center of the shock to the circle, the tangent stress at point $\mathrm{K}_{1}$ is $\sigma_{y}$, at the point $\mathrm{K}_{2}$ is $\sigma_{x}$ and the normal stress at the point $\mathrm{K}_{1}$ is $\sigma_{x}$, at the point $\mathrm{K}_{2}$ is $\sigma_{y}$. The corresponding numerical values of the normal stresses are in Tab. 6. and tensile stresses are in Tab. 7.

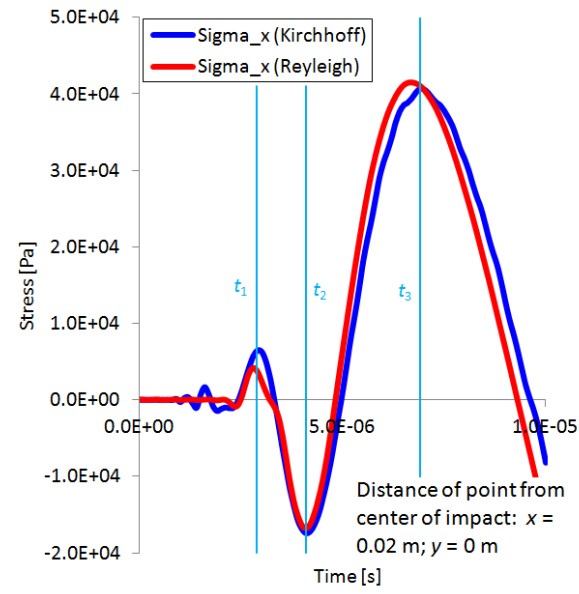

Fig. 12. Normal stresses $\sigma_{x}$ in point $K_{1}$ for Kirchchoff's and Reyleigh's model

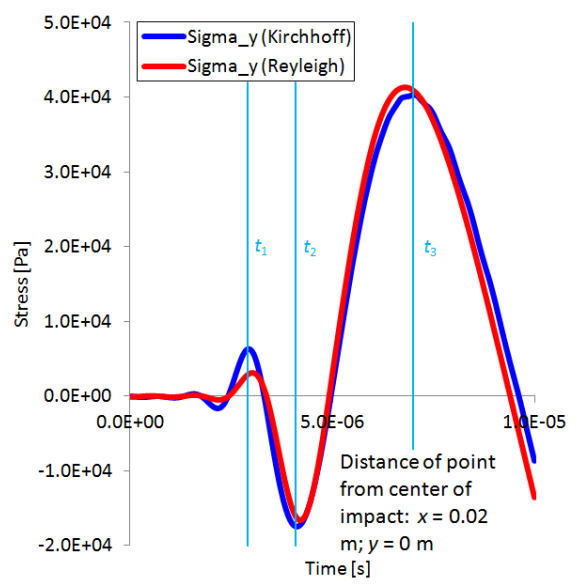

Fig. 13. Normal stresses $\sigma_{y}$ in point $\mathrm{K}_{2}$ for Kirchchoff's and Reyleigh's model 
Table 6. Normal stresses $\left(\sigma_{x}, \sigma_{y}\right)$ in point $\mathrm{K}_{1}$ and $\mathrm{K}_{2}$

\begin{tabular}{|c|c|c|c|c|c|}
\hline \multicolumn{2}{|c|}{ Point } & \multicolumn{2}{|c|}{ K$_{1}$} & \multicolumn{2}{c|}{ K$_{\mathbf{2}}$} \\
\hline \multicolumn{2}{|c|}{ Time [s] } & \multicolumn{2}{|c|}{ Normal stress $\boldsymbol{\sigma}_{\boldsymbol{x}}[\mathrm{Pa}]$} & \multicolumn{2}{c|}{ Normal stress $\boldsymbol{\sigma}_{\boldsymbol{y}}[\mathrm{Pa}]$} \\
\cline { 3 - 6 } & & Kirchhoff & Reyleigh & Kirchhoff & \multicolumn{1}{c|}{ Reyleigh } \\
\hline$t_{1}$ & $2.900 \times 10^{-6}$ & $6.307 \times 10^{3}$ & $3.650 \times 10^{3}$ & $6.307 \times 10^{3}$ & $2.815 \times 10^{3}$ \\
\hline$t_{2}$ & $4.100 \times 10^{-6}$ & $-1.745 \times 10^{4}$ & $-1.680 \times 10^{4}$ & $-1.745 \times 10^{4}$ & $-1.619 \times 10^{4}$ \\
\hline$t_{3}$ & $6.900 \times 10^{-6}$ & $4.037 \times 10^{4}$ & $4.101 \times 10^{-4}$ & $4.037 \times 10^{4}$ & $4.045 \times 10^{-4}$ \\
\hline
\end{tabular}

For waveforms normal stress is evident that the magnitude of the stree at the Kirchhoff model is identical on both points. For Rayleigh model are noticeable differences, which range from $2 \%$ at time $t_{3}$, up to $13 \%$ at time $t_{1}$. These differences are minimal and can be attributed to inaccuracies. As for the magnitude of the stress, the differences between Rayleigh and Kirchhoff are quite significant in a short time, which can be attributed to the influence of the cross-sectional rotation and thus to the more accurate Rayleigh calculation.

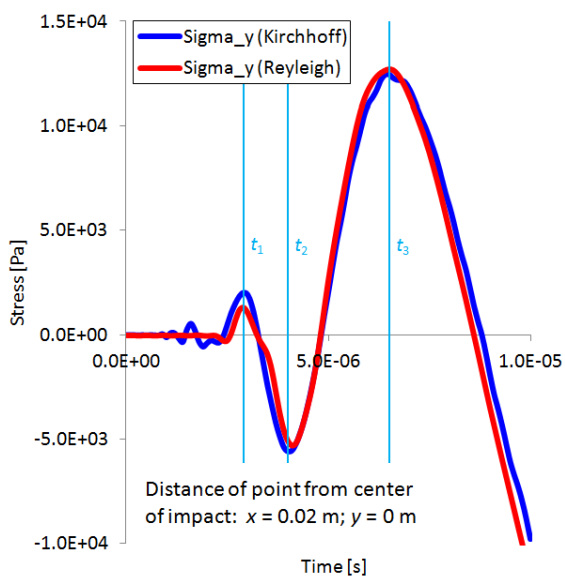

Fig. 14. Tangent stresses $\sigma_{y}$ in point $\mathrm{K}_{1}$ for Kirchchoff's and Reyleigh's model

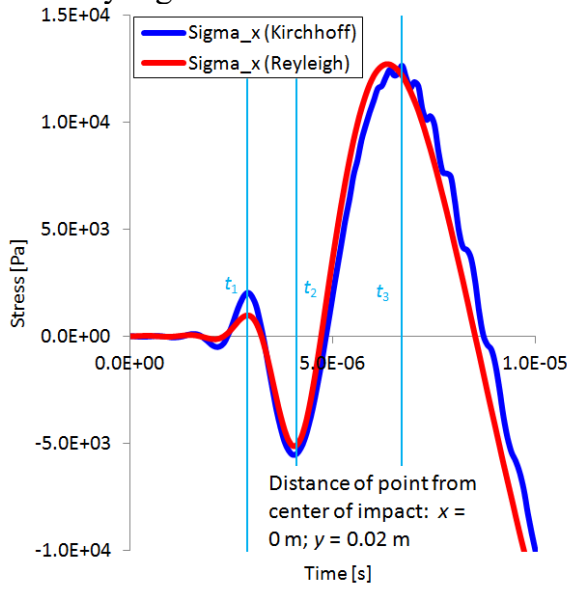

Fig. 15. Tangent stresses $\sigma_{x}$ in point $\mathrm{K}_{2}$ for Kirchchoff's and Reyleigh's model

Table 7. Tangent stresses $\left(\sigma_{x}, \sigma_{y}\right)$ in point $\mathrm{K}_{2}$ and $\mathrm{K}_{1}$

\begin{tabular}{|c|c|c|c|c|c|}
\hline \multicolumn{2}{|c|}{ Point } & \multicolumn{2}{c|}{$\mathbf{K}_{\mathbf{2}}$} & \multicolumn{2}{c|}{$\mathbf{K}_{\mathbf{1}}$} \\
\hline \multicolumn{2}{|c|}{ Time [s] } & \multicolumn{2}{c|}{ Tangent stress $\boldsymbol{\sigma}_{\boldsymbol{x}}[\mathrm{Pa}]$} & \multicolumn{2}{c|}{ Tangent stress $\boldsymbol{\sigma}_{\boldsymbol{y}}[\mathrm{Pa}]$} \\
\cline { 3 - 6 } & Kirchhoff & Reyleigh & Kirchhoff & Reyleigh \\
\hline$t_{1}$ & $2.900 \times 10^{-6}$ & $2.036 \times 10^{3}$ & $1.654 \times 10^{3}$ & $2.030 \times 10^{3}$ & $1.338 \times 10^{3}$ \\
\hline$t_{2}$ & $4.100 \times 10^{-6}$ & $-5.490 \times 10^{3}$ & $-5.107 \times 10^{3}$ & $-5.578 \times 10^{3}$ & $-5.060 \times 10^{3}$ \\
\hline$t_{3}$ & $6.700 \times 10^{-6}$ & $1.265 \times 10^{4}$ & $1.146 \times 10^{4}$ & $1.265 \times 10^{4}$ & $1.372 \times 10^{4}$ \\
\hline
\end{tabular}

In the tangent stresses waveforms, the situation is similar. Rayleigh's model, which, unlike the Kirchhoff model, is considering cross-sectioning is more accurate. The differences between Kirchhoff and Rayleigh models are very small and can be attributed to inaccuracies when rounding off in the calculation program.

\section{Conclusion}

The article compares the course of displacements, velocities and stresses in impact loading of thin isotropic plates. From the above values, it can be deduced that the shock wave propagates evenly along the circles from the shock center, so it is possible to state that it is an isotropic material. 
The analytical solution was performed in the MATLAB programming environment for Kirchhoff and Rayleigh's thin plate model. The impact force on the plate was realized by an impact that hit the geometric center of the plate. The impact was $5 \mathrm{~mm}$ in diameter, the impact force was $1 \mathrm{~N}$. Subsequently, we compared the displacements, velocities and tensions of both models at points $\mathrm{K}_{1}$ and $\mathrm{K}_{2}$. The points were distant from the center of impact (geometric center of the plate) at a distance of $0.02 \mathrm{~m}$ in the direction $x\left(\mathrm{~K}_{1}\right)$ and direction $y\left(\mathrm{~K}_{2}\right)$.

The solution was an isotropic thin plate measuring $0.2 \times 0.1 \times 0.002 \mathrm{~m}$. The plate was about perimeter fixed. The plate material was Al 99.9, the specified material values of $E_{x}=E_{y}=E_{z}=E, \mu_{x}=\mu_{y}=\mu_{z}=\mu$ are given in the Tab. 1 . The time courses of the individual variables, i.e., the displacements, velocities and stresses at $\mathrm{K}_{1}$ and $\mathrm{K}_{2}$, are almost staggered for both geometric models (Kirchchoff, Rayleigh). Differences between models do not exceed $15 \%$. The tables show the values of the variables at times $t_{1}, t_{2}$ and $t_{3}$. At time $t_{1}$, the individual values for the two models differ, as the Kirchoof model only considers vertical displacements and their corresponding inertial effects, therefore has a different initial course than Rayleigh's model, which is expanded by the influence of the cross-sectional rotation.

It can be stated that the values given in the Rayleigh model are more accurate as it considers more parameters. It can be concluded from this that, when further expansion (i.e. the calculation according to Flügge and in particular according to Timoshenko-Mindlina), the values are even more accurate.

The extension of this theory on the composite plate (orthotropic) is important for the new design in many fields, it is assumed that the increase utilization of composite plate and shell elements.

The article was supported by grant number UJEP-SGS-2018-48-002-2 and UJEP-IGS-2018-48002-1, Czech Republic.

\section{References}

1. J. Volek, Nestacionární napjatost tenké desky vyvolané přičnou osamělou silou, Bulletin vědeckých, výzkumných a pedagogických prací ústavu za rok 2000, Ústav techniky a řízení výroby, UJEP, Ústí nad Labem, (2000)

2. Alfrey, T.: Non-homogeneous stresses in visco-elastic media. Q. Appl. Math. 2, pp. 113119, 1944.

3. R. Brepta, M. Okrouhlík, F. Valeš, Vlnové a rázové děje v pevných tělesech a metody jejich řě̌ení, 1. vydání, Praha: Academia, 172 s., (1985)

4. I. Babuska., L. Li, The problem of plate modelling. Theoretical and computional results. Comput. Methods Applied Mech. Engrg. 100, pp 249-273 (1992)

5. R. Lenhard, Numerical simulation device for the transport of geothermal heat with forced circulation of media, in: Fourth Global Conference on PCO 2010, Kuching, Sarawak, Malaysia, ISBN: 978-983-44483-32, (2010)

6. F. Klimenda, J. Soukup, M. Zmindak, Deformation of Aluminium Thin Plate, Manufacturing Technology, Vol. 16, No 1, pp. 124-129, ISSN 1213-2489, (2016)

7. Huffington, N., J., Hoppmann, W., J.: On the transverse vibrations of rectangular orthotropic plates. Journal Applied Mechanics, vol. 25, 1958, pp. 389-395.

8 Bathe, K., J.: Finite Element Procedures, Prentice Hall, Inc. (1996) 